\title{
$\alpha$-TEA cooperates with chemotherapeutic agents to induce apoptosis of p53 mutant, triple-negative human breast cancer cells via activating p73
}

Richa Tiwary ${ }^{1 \dagger}$, Weiping $\mathrm{Yu}^{1{ }^{*+}}$, Bob G Sanders ${ }^{1}$, Kimberly Kline ${ }^{2}$

\begin{abstract}
Introduction: Successful treatment of p53 mutant, triple-negative breast cancers (TNBC) remains a daunting challenge. Doxorubicin (DOXO) and cisplatin (CDDP) are standard-of-care treatments for TNBC, but eventually fail due to acquired drug resistance and toxicity. New treatments for overcoming drug resistance and toxicity in p53 mutant, TNBC are therefore badly needed. Unlike p53, p73 - a member of the p53 family - is usually not mutated in cancers and has been shown to regulate p53-mediated apoptotic signaling in p53-deficient cancers. Therefore, identification of anticancer agents that can activate p73 in p53-deficient cancers may provide a chemotherapeutic approach for treatment of p53 mutant cancers. Here we report on the reconstitution of the p53 tumor suppressor pathway in a p53-independent manner via p73 with combination treatments of $\alpha$-TEA, a small bioactive lipid, plus DOXO or CDDP.

Methods: p53 mutant, TNBC cell lines MDA-MB-231, BT-20 and MDA-MB-468 were used to evaluate the anticancer effect of chemotherapeutic drugs and $\alpha$-TEA using annexin V (FITC)/PI staining, western blot analyses, RT-PCR and siRNA knockdown techniques.

Results: Combination treatments of $\alpha$-TEA plus DOXO or CDDP act cooperatively to induce apoptosis, caspase- 8 and caspase-9 cleavage, p73, phospho-c-Ab1 and phospho-JNK protein expression, and increase expression of p53 downstream mediators; namely, death receptor-5, CD95/APO-1 (Fas), Bax and Noxa, as well as Yap nuclear translocation - plus reduce expression of Bcl-2. Knockdown of p73, c-Abl, JNK or Yap using siRNAs shows that p73 plays a critical role in combination treatment-enhanced apoptosis and the expression of pro-apoptotic and antiapoptotic mediators, and that c-Abl, JNK and Yap are upstream mediators of p73 in combination treatment responses.
\end{abstract}

Conclusions: Data show that $\alpha$-TEA in combination with DOXO or CDDP synergistically enhances apoptosis in TNBC via targeting p53-mediated genes in a p73-dependent manner, and that p73 responses are downstream of c-Abl, JNK and Yap.

\section{Introduction}

Successful treatment of triple-negative breast cancers (TNBC) (estrogen receptor (ER)-negative, progesterone receptor-negative and Her-2-negative), that are also p53 mutant remains elusive. Unfortunately, the anticancer

\footnotetext{
* Correspondence: weiping@mail.utexas.edu

† Contributed equally

${ }^{1}$ School of Biological Sciences/C0900, University of Texas, 1 University

Station, Austin, TX 78712, USA

Full list of author information is available at the end of the article
}

efficacy of commonly used chemotherapeutic agents for TNBC, including doxorubicin (DOXO) and cisplatin (CDDP), are limited due to acquired drug resistance and toxicities $[1,2]$.

DOXO and CDDP are DNA-damaging drugs that exert their anticancer actions via inhibition of cellular proliferation and induction of cell death by apoptosis $[3,4]$. The tumor suppressor gene p53 plays a central role in the anticancer actions of DNA-damaging agents. Loss of

\section{Biomed Central}

(c) 2011 Tiwary et al.; licensee BioMed Central Ltd. This is an open access article distributed under the terms of the Creative Commons Attribution License (http://creativecommons.org/licenses/by/2.0), which permits unrestricted use, distribution, and reproduction in any medium, provided the original work is properly cited. 
wild-type p53 functions leads to resistance to DNA-damaging agents, such as DOXO and CDDP [5,6]. Identification of anticancer agents that target p53 downstream genes via p53-independent mechanisms is of major clinical relevance, especially since p53 deficiency is a hallmark of many different cancer types.

p73 is a member of the p53 gene family [7]. Unlike p53 [8], p73 is rarely mutated or lost in cancers [9]. Although p53-deficient cancers are less responsive to chemotherapy, they are typically not completely drug resistant because other p53 family members, such as p73, can replace p53 function in response to DNA damage [9-11]. Since p73 is usually not mutated in cancers and has been shown to regulate p53 target genes in p53-deficient cancers, identification of anticancer agents that can activate p73 in p53-deficient cancers will provide a chemotherapeutic approach for treatment of drug-resistant p53 mutant cancers.

$\alpha$-TEA (2,5,7,8-tetramethyl-2R-(4R,8R,12-trimethyltridecyl) chroman-6-yloxyacetic acid, known as RRR- $\alpha$ tocopherol ether-linked acetic acid analog or RRR- $\alpha$-tocopheryloxyacetic acid) is a nonhydrolyzable ether analog of RRR- $\alpha$-tocopherol [12]. $\alpha$-TEA has been shown to be a potent pro-apoptotic agent both in vitro and in vivo in breast, prostate and ovarian cancer cells [12-20]. Recently, $\alpha$-TEA has been shown to delay tumor onset and to inhibit the progression and metastatic spread in a clinically relevant model of spontaneous mammary cancer, further highlighting the translational potential of this anticancer agent [14]. Mechanisms involved in $\alpha$-TEA-induced apoptosis include activation of JNK/c-Jun, p73/NOXA and Fas/ death receptor-5 (DR5), and suppression of c-FLIP-L, survivin and phospho-Akt (pAkt) - leading to death receptormediated caspase- 8 activation and mitochondria-dependent apoptosis [15-20].

Data presented here show that $\alpha$-TEA in combination with DOXO or CDDP significantly enhances apoptosis of p53 mutant, triple-negative human breast cancer cells by targeting p73-mediated p53-dependent pro-apoptotic and anti-apoptotic genes via c-Abl, JNK and Yap signaling pathways.

\section{Materials and methods Chemicals}

$\alpha$-TEA was made in-house as previously described [12]. DOXO and CDDP were purchased from Sigma (San Diego, CA, USA). Phosphoinositide 3-kinase inhibitor (wortmannin) was purchased from Cell Signaling Technology (Beverly, MA, USA).

\section{Cell culture}

p53 mutant, triple-negative human breast cancer cell lines MDA-MB-231, BT-20 and MDA-MB-468 were purchased from the American Type Culture Collection (Manassas, VA, USA). MDA-MB-231 and BT-20 cells were cultured in MEM media with 10\% FBS, and MDA-MB-468 cells were cultured in Dulbecco's MEM media with $10 \%$ FBS. All three p53 mutant TNBC cell lines (ER', PR-', HER2 ${ }^{-1}$

${ }^{\text {low }) ~ u s e d ~ i n ~ t h e s e ~ s t u d i e s ~ w e r e ~ o r i g i n a l l y ~ o b t a i n e d ~ f r o m ~}$ human samples so no isogenic counterparts expressing wildtype p53, ER and progesterone receptor are available for use as controls. For experiments, FBS was reduced to $2 \%$ to better mimic low in vivo serum exposure and cells were allowed to attach overnight before treatment. $\alpha$-TEA (40 mM) was dissolved in ethanol as a stock solution. Concentrations of ethanol used in vehicle treatments were 0.025 to $0.05 \%(\mathrm{v} / \mathrm{v})$ to match the ethanol content in the different final concentrations of $\alpha$-TEA treatments. DOXO and CDDP were dissolved in $\mathrm{H}_{2} \mathrm{O}$.

\section{Quantification of apoptosis}

Apoptosis was quantified by annexin V-FITC/PI assays following the manufacturer's instructions. Fluorescence was measured using fluorescence-activated cell sorter analyses with a FACSCalibur flow cytometer, and data were analyzed using CellQuest software (BD Biosciences, San Jose, CA, USA). Cells displaying phosphatidylserine on their surface (that is, positive for annexin- $\mathrm{V}$ fluorescence) were considered apoptotic.

\section{Nuclear and cytoplasmic fractionation}

Cytoplasmic and nuclear fractions were prepared as previously described [21]. Briefly, whole cell lysates were centrifuged to obtain supernatant and pellet. The supernatant was centrifuged again and the resulting supernatant was used as the cytosolic fraction. The pellet was layered over a cushion of $1 \mathrm{ml}$ sucrose buffer and centrifuged. The final pellet, lysed using RIPA buffer, was used as the nuclear fraction.

\section{Western blot analyses}

Whole cell protein lysates were prepared and western blot analyses were conducted as described previously [22]. Proteins (20 to $50 \mu \mathrm{g} / \mathrm{lane}$ ) were separated by SDSPAGE and transferred to nitrocellulose (Optitran BA-Ssupported nitrocellulose; Schleicher and Schuell, Keene, $\mathrm{NH}$, USA). Antibodies to the following proteins were used: poly(ADP-ribose) polymerase (PARP), Fas, Bcl-2, Bax, total JNK and phospho-JNK (pJNK) (Santa Cruz Biotechnology, Santa Cruz, CA, USA); p73 and NOXA (Imgenex, San-Diego, CA, USA); and pYap (Ser-127), Yap, p-cAbl (Tyr-245), c-Abl, pAkt (Ser-473), caspase-8, caspase-9, DR5 and glyceraldehyde-3-phosphate dehydrogenase (Cell Signaling Technology).

\section{RT-PCR detection of Fas, DR5, Bax, Noxa and Bcl-2 mRNA} expression

Total RNA was extracted using an RNA isolation kit (Qiagen Inc., Valencia, CA, USA). Semi-quantitative analyses were conducted to detect Fas, DR5, Bax, Noxa and Bcl-2 
Table 1 Primer sequences

\begin{tabular}{|c|c|c|}
\hline Gene & Forward primer & Reverse primer \\
\hline Fas & 5'-CAATGGGGATGAACCAGACTGC-3' & 5'-GGCAAAAGAAGAAGACAAAGCC-3' \\
\hline DR5 & 5'-GCCTCATGGACAATGAGATAAAGGTGGCT-3' & 5'-CCAAATCTCAAAGTACGCACAAACGG-3' \\
\hline Bax & 5'-AGTAACATGGAGCTGCAGAGGATG-3' & 5'-AGGAGGCTTGAGGAGTCTCACC-3' \\
\hline Noxa & 5'-CGTGTGTAGTTGGCATCTCC-3' & 5'-AAGGAGTCCCCTCATGCAAG-3' \\
\hline $\mathrm{BCl}-2$ & 5'-CCTGTGGATGACTGAGTACC-3' & 5'-GAGACAGCCAGGAGAAATCA-3' \\
\hline$\beta$-actin & 5'-GGCGGCACCACCATGTACCCT-3" & 5'-AGGGGCCGGACTCGTCATACT-3' \\
\hline
\end{tabular}

mRNA by RT-PCR using the housekeeping gene $\beta$-actin as control. Total RNA was reverse transcribed to cDNA using Superscript RTase (250 U; Invitrogen, Carlsbad, CA, USA) following the manufacturer's instructions. cDNA was used per PCR reaction with Taq PCR Master Mix Kit (Qiagen Inc.) plus $10 \mu \mathrm{M}$ oligonucleotide primer pairs (Invitrogen). The primer sequences are presented in Table 1.

\section{RNA interference}

A scrambled RNA duplex purchased from Ambion (Austin, TX, USA) that does not target any known mouse, rat or human gene was used as the nonspecific negative control for interfering RNA (referred to as control siRNA). Transfection of MDA-MB-231 cells with siRNA to p73, c-Abl, JNK, Yap or control (Ambion) was performed in 100 -mm cell culture dishes at a density of $2 \times 10^{6}$ cells/ dish using Lipofectamine 2000 (Invitrogen) and siRNA duplex, resulting in a final siRNA concentration of 30 $\mathrm{nM}$ following the company's instructions. After 1 day of exposure to transfection mixture, the cells were re-cultured in a $100-\mathrm{mm}$ dish at $2 \times 10^{6}$ cells/dish and incubated for 1 day followed by treatment.

\section{Statistical analysis}

Apoptosis data were analyzed using one-way analysis of variance followed by the Tukey test for comparison of more than two treatments or a two-tailed Student $t$ test for comparison between two treatments to determine statistical differences. Differences were considered statistically significant at $P<0.05$.

\section{Results}

$\alpha-$ TEA, DOXO and CDDP induce apoptosis in p53 mutant, human TNBC cells

The sensitivity of three p53 mutant, TNBC lines (MDAMB-231, BT-20 and MDA-MB-468) to apoptosis induced by $\alpha$-TEA, DOXO and CDDP was evaluated by determining half-maximal effective concentration values for apoptosis (Table 2). Data show that MDA-MB-468 cells exhibit the most sensitive phenotype and MDAMB-231 cells exhibit the most resistant phenotype to apoptosis induced by DOXO and CDDP among the three cell lines. The sensitivity of the three cell lines to $\alpha$-TEA-induced apoptosis, however, is similar.
$\alpha$-TEA cooperates with DOXO and CDDP to induce apoptosis of p53 mutant, TNBC cells

Based on the half-maximal effective concentration values for apoptosis presented in Table 2, the MDA-MB-231 and $\mathrm{BT}-20$ cell lines that are more resistant to DOXO and CDDP were chosen to study the combinational effects of $\alpha$-TEA + DOXO or $\alpha$-TEA + CDDP on apoptosis induction. Data showed that $\alpha$-TEA at 10 and $20 \mu \mathrm{M}$ significantly enhanced apoptosis in combination with DOXO and CDDP in MDA-MB-231 and BT-20 cells, respectively, in comparison with individual treatments (Figure $1 \mathrm{a}$ to $1 \mathrm{~d}$ ). The mean combination index for the combination of $\alpha$-TEA + DOXO was $0.41 \pm 0.07$ and $0.53 \pm 0.05$ for MDA-MB-231 and BT-20 cells, respectively (Table 3$)$. The mean combination index for the combination of $\alpha$-TEA + CDDP was $0.45 \pm 0.10$ and $0.75 \pm 0.08$ in MDA-MB-231 and BT-20 cells, respectively (Table 3 ). These data demonstrate that combinations of $\alpha$-TEA + DOXO or $\alpha$-TEA + CDDP synergistically induce apoptosis in both cell lines. Western blot analyses show that $\alpha$-TEA at $20 \mu \mathrm{M}$ cooperates with DOXO and CDDP to induce elevated levels of cleaved caspase-8, caspase-9, and PARP in both cell lines (Figure 2a,b), indicating that apoptosis induced by these combinations involves both caspase- 8 and caspase- 9 activation.

\section{p73 protein level is upregulated by $\alpha$-TEA + DOXO or $\alpha-$ TEA + CDDP combinations and is involved in combination-induced apoptosis}

Since DOXO and CDDP as well as $\alpha$-TEA have been shown to induce p73 upregulation in breast cancer

Table 2 Half-maximal effective concentration values for apoptosis

\begin{tabular}{llll}
\hline Cell line & $\alpha$-TEA $(\mu \mathrm{M})$ & DOXO $(\mu \mathrm{M})$ & CDDP $(\mu \mathrm{M})$ \\
\hline MDA-MB-231 & 41.7 & 46.5 & 70.8 \\
BT-20 & 45.4 & 25.7 & 64.0 \\
MDA-MB-468 & 35.4 & 8.5 & 40.7
\end{tabular}

Cells were treated with different concentrations of $\alpha$-TEA, doxorubicin (DOXO), and cisplatin (CDDP) for 24 hours. Apoptosis was determined by annexin VFITC/PI staining/fluorescence-activated cell sorter analysis as described in Material and methods. The concentration that achieved 50\% apoptosis (halfmaximal effective concentration) was determined using commercially available software (Calcusyn; Biosoft, Manchester, UK). 


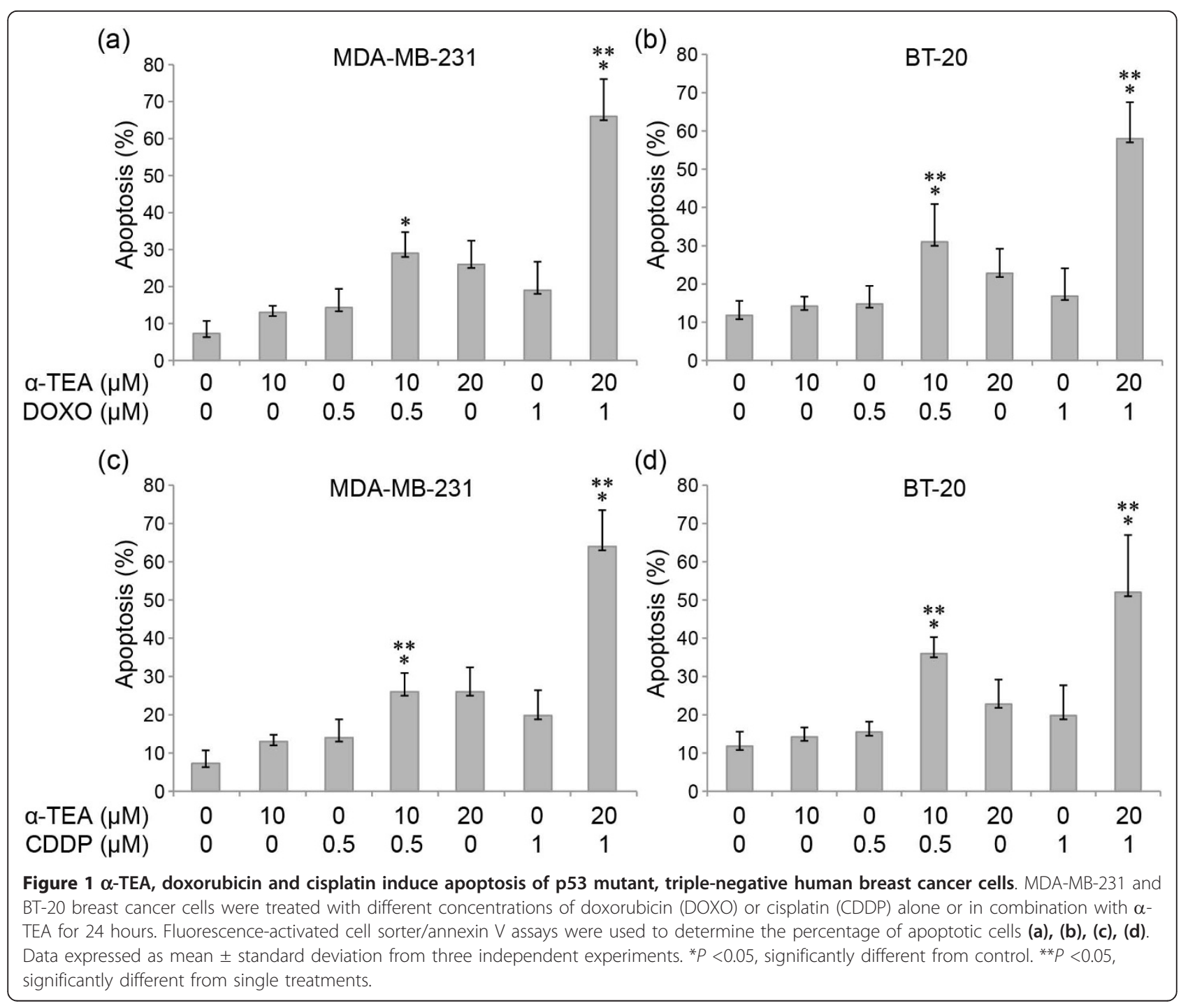

cells $[11,17,23]$, the combination of $\alpha$-TEA + DOXO or $\alpha$-TEA + CDDP was investigated for ability to cooperatively enhance p73 protein expression. Single treatments with DOXO, CDDP or $\alpha$-TEA at sub-apoptotic levels for 24 hours slightly increased p73 protein expression above control levels, whereas combinations at the same levels markedly enhanced p73 protein expression in comparison with single treatments in both MDA-MB-231 and BT-20 cells (Figure 3a,b). siRNA to p73 significantly reduced the ability of combination treatments to induce apoptosis as determined by annexin V (Figure 3c) and PARP analyses (Figure 3d) in MDA-MB-231 cells. Western blot data show that siRNA to p73 effectively silenced p73 protein expression (Figure 3d). These data indicate that p73 activation by combination treatments is critical for induction of cell death by apoptosis.

\section{Combinations of $\alpha$-TEA + DOXO or $\alpha$-TEA + CDDP} upregulate pro-apoptotic and downregulate antiapoptotic mediators at both mRNA and protein levels Published data show that p73 can regulate p53-dependent genes in p53-deficient cells [11]. To better understand the cellular events involved in p73-mediated apoptosis in combination treatments, mRNA and protein expression of p53-mediated pro-apoptotic mediators DR5, Fas, Bax, and Noxa, and anti-apoptotic mediator Bcl-2 were examined. Combinations of $\alpha$-TEA + DOXO or $\alpha$-TEA + CDDP enhanced DR5, Fas, Bax and Noxa mRNA (Figure 4a,b) and protein expression (Figure 4c, d), and decreased Bcl-2 mRNA (Figure 4a,b) and protein expression (Figure 4c,d) in MDA-MB-231 and BT-20 cells. siRNA knockdown of p73 was performed to determine whether expression levels of these mediators were regulated by p73. siRNA to p73 in MDA-MB-231 cells 
Table 3 Combination index of apoptosis

\begin{tabular}{|c|c|c|c|c|c|c|}
\hline \multirow[b]{2}{*}{ Cell line } & \multirow[b]{2}{*}{$\begin{array}{l}\alpha \text {-TEA: } \\
\text { drug }^{b}\end{array}$} & \multicolumn{5}{|c|}{ Combination index ${ }^{a}$} \\
\hline & & $\mathrm{ED}_{50}$ & $\mathrm{ED}_{75}$ & $\mathrm{ED}_{90}$ & Mean $\pm S D^{c}$ & \\
\hline \multicolumn{7}{|l|}{ DOXO } \\
\hline $\begin{array}{l}\text { MDA- } \\
\text { MB-231 }\end{array}$ & $20: 1$ & 0.48 & 0.40 & 0.35 & $0.41 \pm 0.07$ & Synergism \\
\hline BT-20 & $20: 1$ & 0.48 & 0.52 & 0.58 & $0.53 \pm 0.05$ & Synergism \\
\hline \multicolumn{7}{|l|}{ CDDP } \\
\hline $\begin{array}{l}\text { MDA- } \\
\text { MB-231 }\end{array}$ & $2: 1$ & 0.55 & 0.44 & 0.36 & $0.45 \pm 0.10$ & Synergism \\
\hline BT-20 & $4: 1$ & 0.68 & 0.74 & 0.84 & $0.75 \pm 0.08$ & Synergism \\
\hline
\end{tabular}

MDA-MB-231 and BT-20 breast cancer cells were treated with different concentrations of $\alpha$-TEA, doxorubicin (DOXO), and cisplatin (CDDP) alone and in combination for 24 hours. Apoptosis was determined using annexin V-FITC/ PI staining/fluorescence-activated cell sorter assay as described in Material and methods. ${ }^{\text {a }}$ For each combination treatment, a combination index was calculated using commercially available software (Calcusyn; Biosoft, Manchester, UK). ${ }^{\text {b}}$ The ratio for the concentrations used in combination

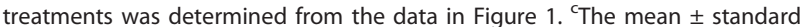
deviation (SD) calculated from the combination index values of the effective dose in $50 \%\left(E D_{50}\right)$, the effective dose in $75 \%\left(E D_{75}\right)$ and the effective dose in $90 \%\left(E_{90}\right)$ of the population. ${ }^{d}$ Combination index value: $<1.0$, synergism; 1.0 , additive effect; $>1.0$, antagonism.

effectively silenced p73 protein expression and blocked the ability of combinations to induce increased levels of DR5, Fas, Bax and Noxa protein, as well as to decrease Bcl-2 protein levels (Figure 4e). These data suggest that combination treatments induce upregulation of pro-apoptotic mediators and downregulation of an anti-apoptotic mediator in a p73-dependent manner in p53 mutant, TNBC MDA-MB-231 and BT-20 cells. Recent studies in our laboratory show that DR5 pro-apoptotic signaling contributes to $\alpha$-TEA-induced apoptosis $[19,20]$. To determine whether DR5 contributes to combination treatmentinduced apoptosis, DR5 was functionally knocked-down with siRNA. Data indicate that silencing DR5 protein expression blocks combination-induced apoptosis as determined by PARP cleavage (Figure 4f).

$\alpha$-TEA cooperates with DOXO or CDDP to upregulate pcAbl and pJNK, upstream mediators of p73

Studies show that p73 can be upregulated upon DNA damage via activation of c-Abl and JNK [23,24]. To understand how p73 is activated by the combination treatments, phosphorylated levels of c-Abl and JNK2/1 were examined. Combinations of $\alpha$-TEA + DOXO or $\alpha$ TEA + CDDP induced increased levels of pc-Abl (Tyr245 ) and pJNK2/1 in both cell lines (Figure 5a,b). siRNA knockdown of c-Abl or JNK significantly reduced the ability of combination treatments to induce apoptosis in MDA-MB-231 cells as determined by annexin V (Figure 5c) and PARP cleavage (Figure 5d). siRNA treatments blocked the ability of combination treatments to increase protein levels of p73 and blocked the ability of combination treatments to increase protein levels of
DR5, Fas, Bax and Noxa, and to decrease the level of Bcl-2 (Figure 5d). siRNA to c-Abl blocked the ability of combination treatments to induce increased levels of pJNK, whereas siRNA to JNK had no effect on the ability of combination treatments to induce increased levels of pc-Abl (Tyr 245) (Figure 5d). These data show that activation of p73 is mediated by c-Abl and JNK in the combination treatments, and suggest that $\mathrm{c}-\mathrm{Abl}$, in part, regulates the phosphorylation status of JNK.

\section{Yap is involved in combination-induced apoptosis}

Since Yap, a transcriptional co-activator Yes-associated protein, can interact with $\mathrm{p} 73$, resulting in enhanced p73 transcriptional activity [25] and stability $[26,27]$, we determined whether Yap contributes to combination-induced apoptosis and increased p73 expression. siRNA knockdown of Yap significantly reduced the ability of combination treatments to induce apoptosis as measured by annexin $\mathrm{V}$ analyses (Figure 6a) and western blot analyses of PARP cleavage (Figure 6b). siRNA to Yap effectively reduced Yap protein levels and blocked combination treatment effects on p73 protein expression, as well as combination effects on DR5, Fas, Bax, Noxa and Bcl-2 protein expression (Figure 6b). These data show that Yap is a key player in combination treatment-induced apoptosis mediated by $\mathrm{p} 73$.

\section{Combination treatments induce Yap nuclear translocation, which is associated with suppression of phosphorylation of Akt and Yap}

Yap activity can be regulated by c-Abl via phosphorylation of Yap at Tyr-357, leading to its stabilization and higher affinity for p73 [28,29]. Furthermore, Yap can be negatively regulated by Akt [29,30]. Akt induces Yap phosphorylation at Ser-127, resulting in Yap cytosolic localization via promoting Yap binding with 14-3-3, resulting in inactivation of Yap [30]. Since $\alpha$-TEA has been shown to decrease pAkt in prostate cancer cells [15], ovarian cancer cells [18], and breast cancer cells (data not shown) we examined the effect of combination treatments on Yap nuclear translocation, as well as on pAkt and pYap expression.

Combination treatments of MDA-MB-231 cells induced increased levels of Yap protein in the nuclear fraction and reduced levels of Yap protein in the cytoplasmic fraction. Histone 1 and glyceraldehyde-3phosphate dehydrogenase were used to evaluate the purity of nuclear and cytoplasmic fractions, respectively, and served as lane load controls (Figure 7a). Furthermore, data show that DOXO and CDDP increased pAkt and pYap protein expression, while $\alpha$-TEA cooperated with DOXO or CDDP to suppress pAkt and pYap in MDAMB-231 (Figure 7b). These data suggest that Yap nuclear 


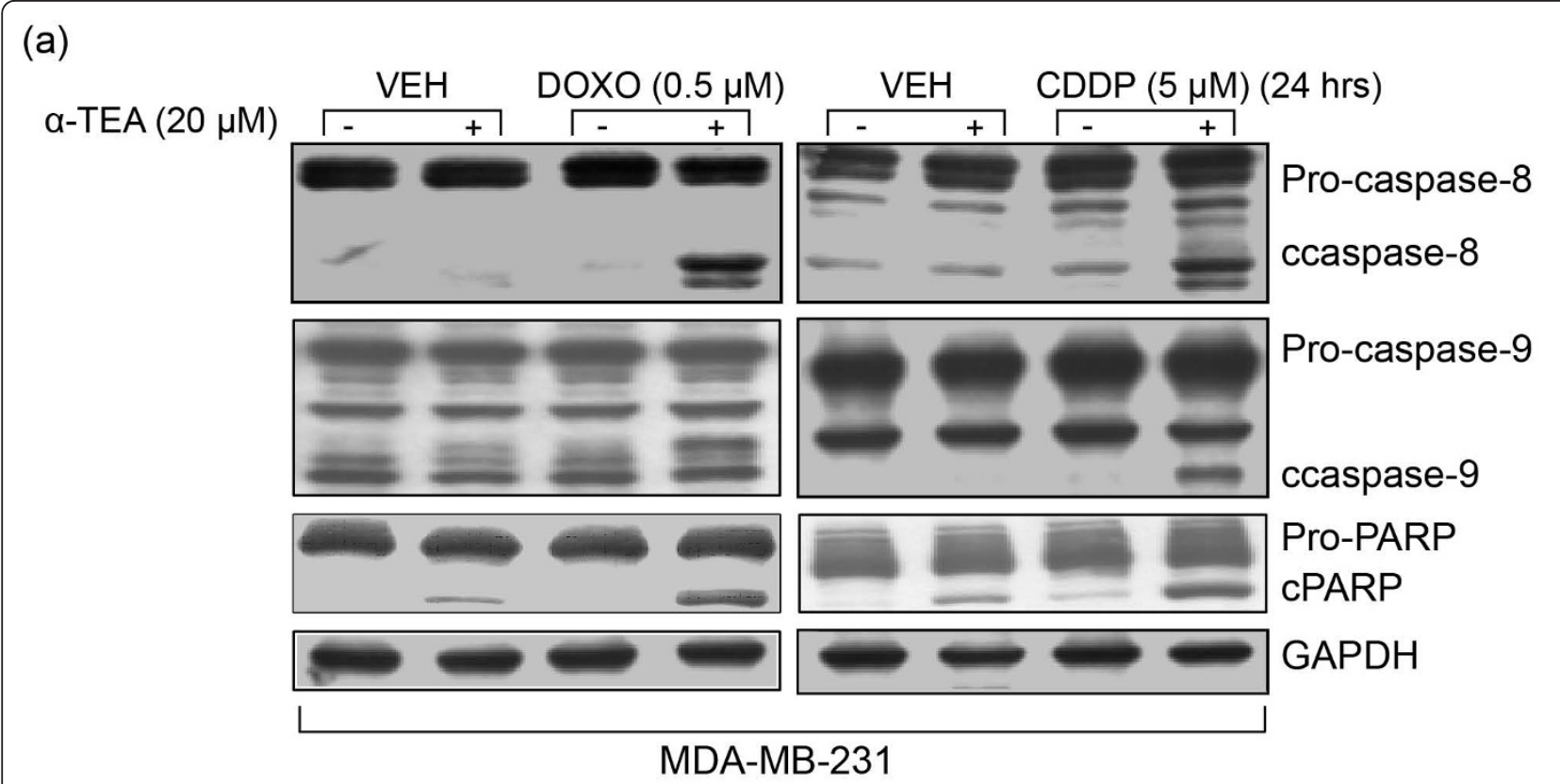

(b)

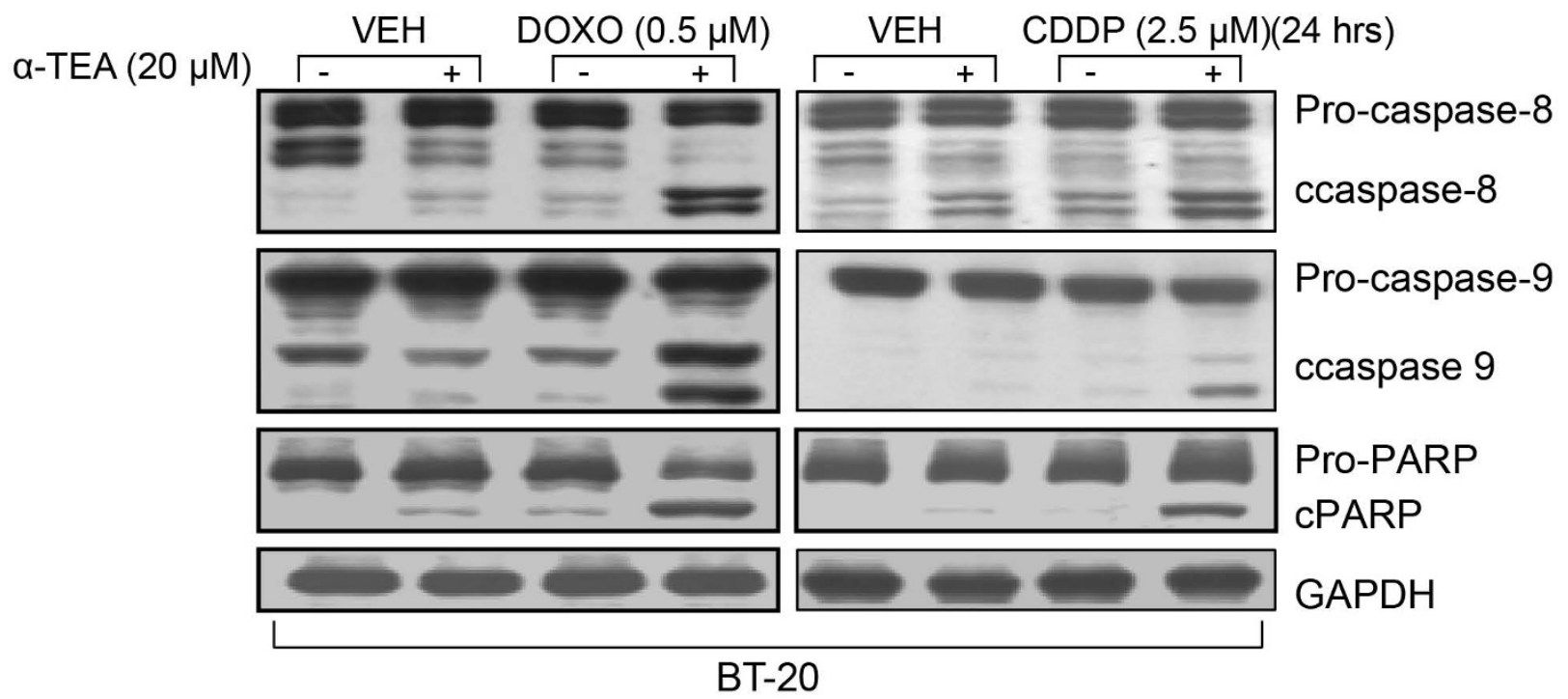

Figure $2 \alpha$-TEA cooperates with doxorubicin and cisplatin to induce cleavage of caspase-8, caspase-9 and poly(ADP-ribose) polymerase. MDA-MB-231 and BT-20 cells were treated with doxorubicin (DOXO) or cisplatin (CDDP) alone or in combination with $\alpha$-TEA for 24 hours. Western blot analyses were used to detect poly(ADP-ribose) polymerase (PARP), caspase-8, and caspase-9 cleavage (a), (b). Data are representative of at least two independent experiments. GAPDH, glyceraldehyde-3-phosphate dehydrogenase; VEH, vehicle.

translocation may partially contribute to p73-mediated effects and that combination treatment downregulation of pAkt correlates with decreased levels of pYap. To assess the role of Akt in DOXO-induced and CDDPinduced p73 protein expression, we examined the impact of phosphoinositide 3-kinase/Akt inhibitor (wortmannin) on DOXO-induced and CDDP-induced 73 protein expression. Data show that wortmannin enhanced
DOXO-induced and CDDP-induced upregulation of p73 protein expression (Figure $7 \mathrm{c}$ ), indicating a role for Akt in DOXO and CDDP increase in 73 expression. Data also show that wortmannin blocked DOXO-induced and CDDP-induced upregulation of pAkt and pYap (Figure $7 \mathrm{c})$, suggesting that suppression of pAkt enhances DOXO-induced and CDDP-induced $\mathrm{p} 73$ expression via downregulation of pYap. 


\section{(a)}

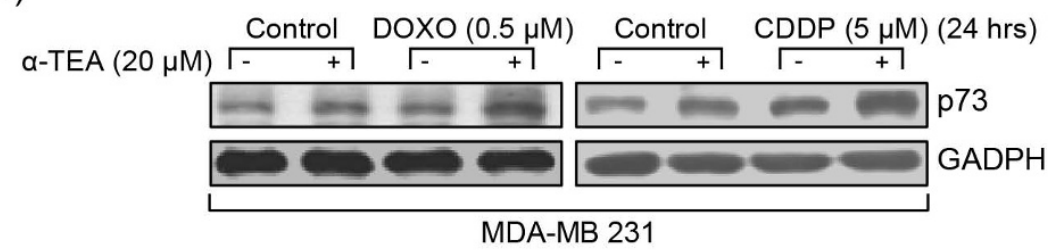

(b)

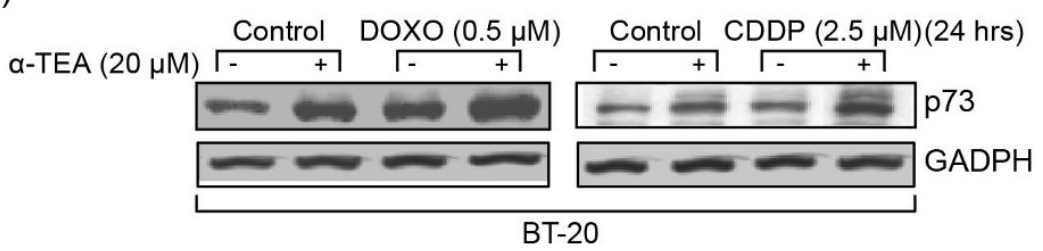

(c)

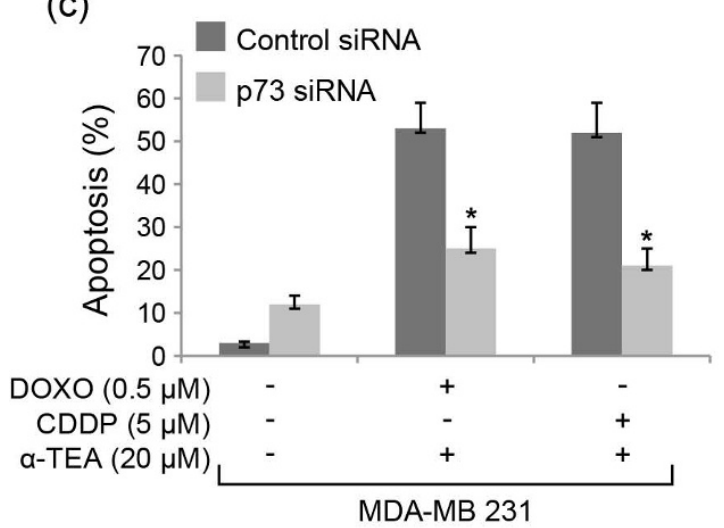

(d)

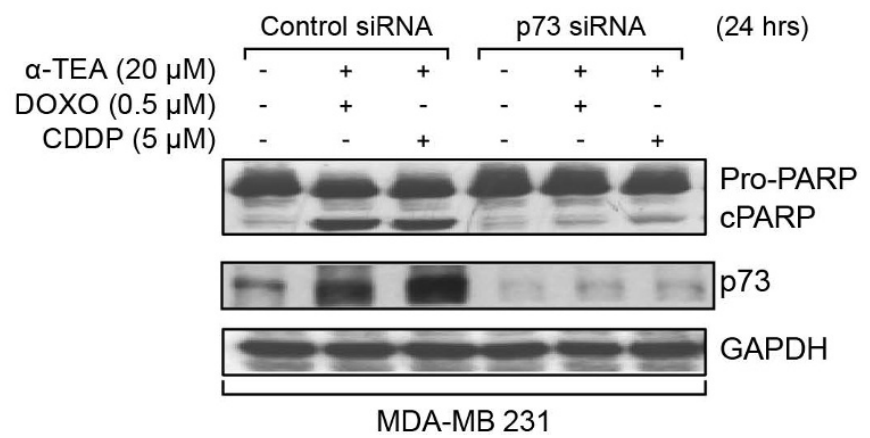

Figure 3 p73 is upregulated by combination treatments and involved in combination-induced apoptosis. MDA-MB-231 and BT-20 cells were treated with $\alpha$-TEA, doxorubicin (DOXO) and cisplatin (CDDP) alone or in combination for 24 hours. Western blot analyses were performed to detect protein levels of p73 with glyceraldehyde-3-phosphate dehydrogenase (GAPDH) serving as loading control (a), (b). MDA-MB-231 cells were transfected with p73 siRNA or control siRNA for 2 days and treated with combinations of $\alpha$-TEA + DOXO or $\alpha$-TEA + CDDP for 24 hours. Fluorescence-activated cell sorter/annexin $V$ assays were used to determine the percentage of apoptotic cells (c). Western blot analyses were used to verify the knockdown efficiency of p73 siRNA and the effect of p73 siRNA on combination-induced poly(ADP-ribose) polymerase (PARP) cleavage (d). Data in (a), (b) and (d) representative of at least two independent experiments; data in (c) expressed as mean \pm standard deviation from three independent experiments. ${ }^{*} P<0.05$, significantly different from control siRNA determined by $t$ test.

\section{Discussion}

p73 is an important target for treating p53 mutant cancers [10,31-33]. The novel findings in the present study are as follows. First, $\alpha$-TEA - a potent anticancer analog of vitamin E - synergizes with DNA-damaging agents DOXO and CDDP to induce apoptosis of human p53 mutant, triple-negative human breast cancer MDA-MB231 and BT-20 cells via targeting p73. Second, combination treatments result in p73-dependent upregulation of pro-apoptotic DR5, Fas, Bax and Noxa, and downregulation of anti-apoptotic mediator Bcl-2 - all of which are p53-mediated apoptotic-related genes. Third, p73 and p73-mediated apoptotic events are regulated by c-Abl, JNK and Yap in combination treatments. Finally, $\alpha$-TEA downregulation of Akt partially contributes to p73 upregulation in combination treatments. Our data therefore, for the first time, identify $\alpha$-TEA as a small bioactive anticancer agent that regulates p53-mediated genes via $\mathrm{p} 53$-independent mechanisms when combined with DNA-damaging agents.

As a transcription factor, p73 shares structural and functional similarities with p53 $[9,32,33]$. In cancer cells that express wildtype p53, p73 has been reported to cooperate with p53 to induce apoptosis [34]; whereas in p53 mutant cancer cells, p73 has been reported to induce apoptosis via activation of p53-inducible genes $[11,35]$. Typically, p53 induces apoptosis via regulating apoptosis-related genes such as DR5, Fas, Bax, Noxa and Bcl-2 [36,37]. p73 is upregulated in response to a subset of DNA-damaging agents, including DOXO, 


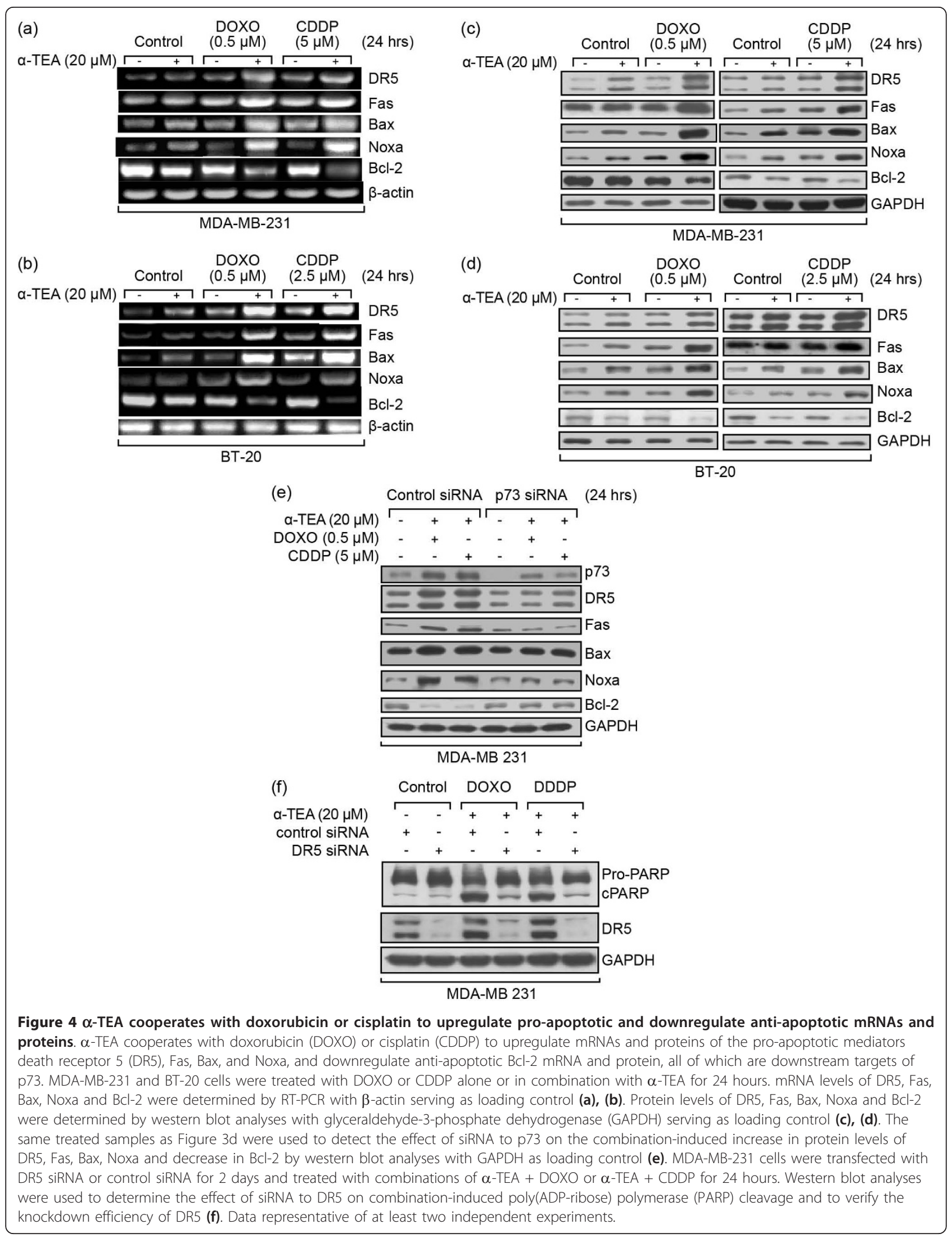




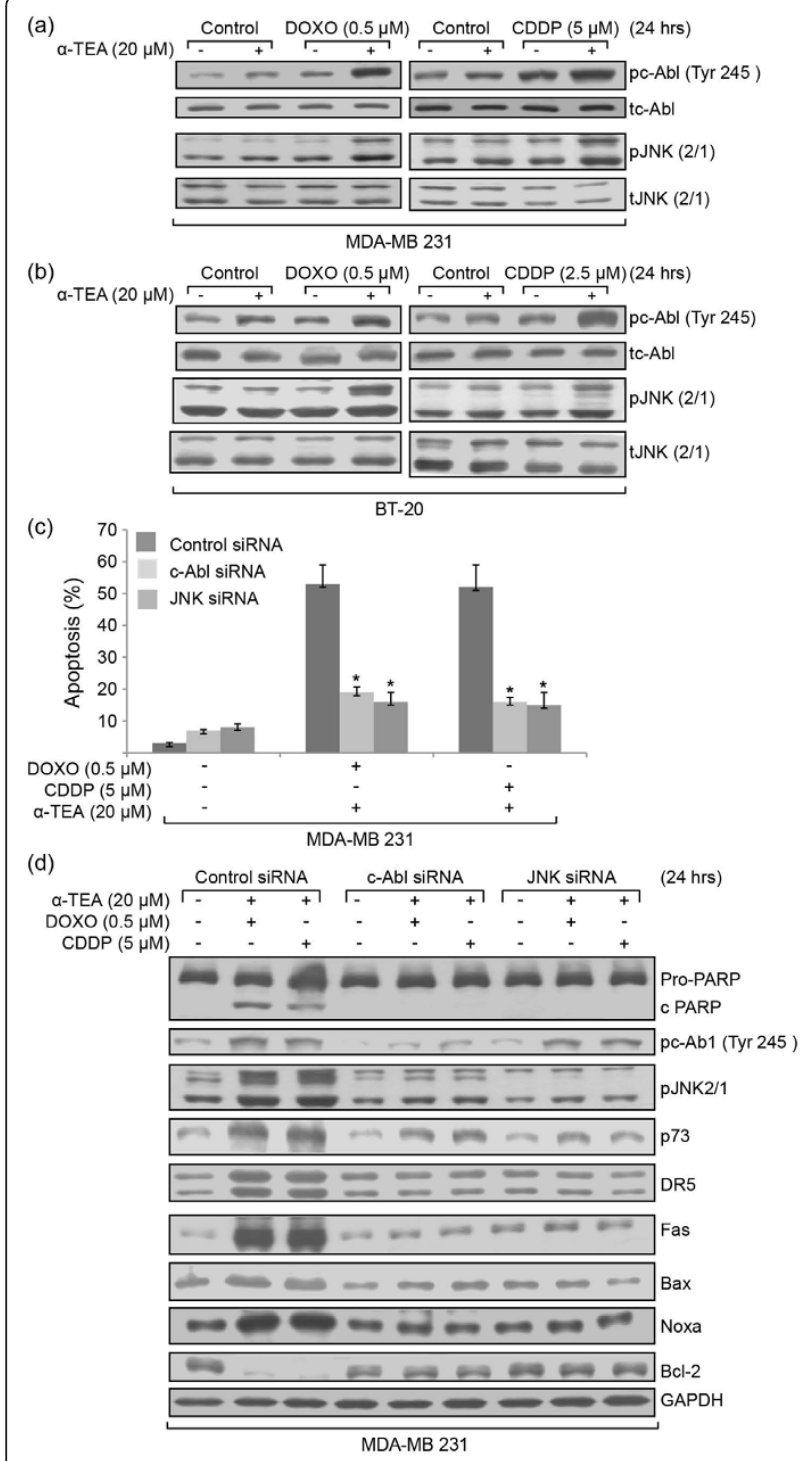

Figure $5 \alpha$-TEA cooperates with doxorubicin or cisplatin to upregulate pc-Abl and pJNK, which can serve as upstream mediators of p73. $\alpha$-TEA cooperates with doxorubicin (DOXO) or cisplatin (CDDP) to upregulate $\mathrm{pc}-\mathrm{Abl}$ and $\mathrm{pJNK}$, which can serve as upstream mediators of p73. MDA-MB-231 and BT-20 cells were treated with DOXO or CIDDP alone or in combination with $\alpha$-TEA for 24 hours. Protein levels of pc-Abl (Tyr-245), total c-Abl (tc-Abl), pJNK2/1, and total JNK2/1 (tJNK2/1) were determined by western blot (a), (b). MDA-MB-231 cells were transfected with c-Abl and JNK siRNAs, as well as control siRNA for 2 days and treated with a combination of $\alpha$-TEA + DOXO or $\alpha$-TEA + CDDP for 24 hours. Apoptosis was determined by annexin V/fluorescence-activated cell sorter (c). Western blot analyses were used to verify the knockdown efficiency of c-Abl and JNK siRNAs and the effect of c-Abl and JNK siRNAs on combination-induced poly(ADP-ribose) polymerase (PARP) cleavage, as well as p73 and p73-mediated death receptor 5 (DR5), Fas, Bax, Noxa and Bcl-2 (d). Data in (a), (b), and (d) representative of at least two independent experiments; data in (c) expressed as mean \pm standard deviation from three independent experiments. ${ }^{*} P<0.05$, significantly different from control siRNA determined by $t$ test. GAPDH, glyceraldehyde-3-phosphate dehydrogenase.
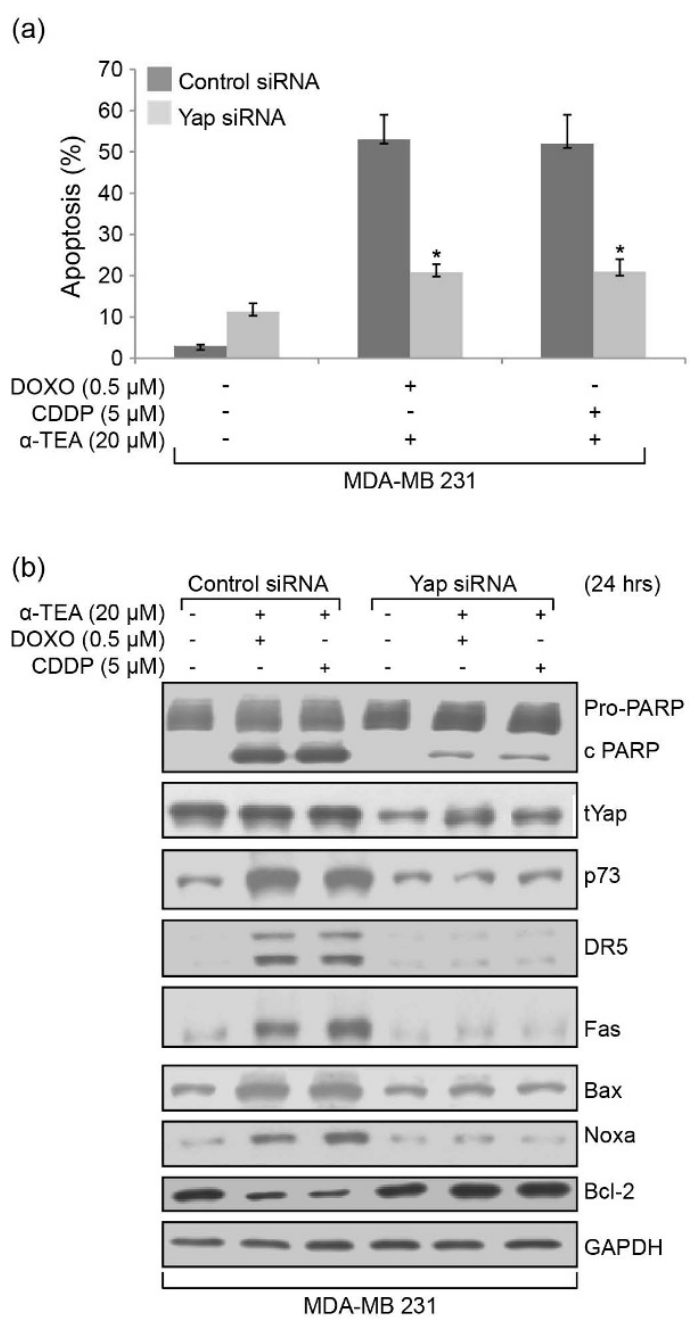

Figure 6 Yap is involved in combination treatment-induced apoptosis. MDA-MB-231 cells were transfected with Yap siRNA or control siRNA for 2 days and treated with combinations for 24 hours. Apoptosis was determined by annexin V/fluorescenceactivated cell sorter (a). Western blot analyses were used to verify the knockdown efficiency of Yap siRNA and the effect of Yap siRNA on combination-induced poly(ADP-ribose) polymerase (PARP) cleavage, as well as p73 and p73-mediated death receptor 5 (DR5), Fas, Bax, Noxa and Bcl-2 (b). Data (a) expressed as mean \pm standard deviation from three independent experiments; data in (b) representative of at least two independent experiments. ${ }^{*} P<0.05$, significantly different from control siRNA determined by $t$ test. CDDP, cisplatin; DOXO, doxorubicin; GAPDH, glyceraldehyde-3phosphate dehydrogenase.

CDDP, camptothecin and etoposide [38]. Several p53mediated apoptosis-related genes have been identified to be regulated by p73, such as Fas, Bax, Bim, Noxa and Puma [17,39-41]. Whether DR5 is a direct target of p73, however, is not well documented. It has been reported that DR5 is regulated by p73 in H1299 human nonsmall lung cancer cells [42]. El-Deiry and coworkers used a high-throughput screen to identify small molecules that 


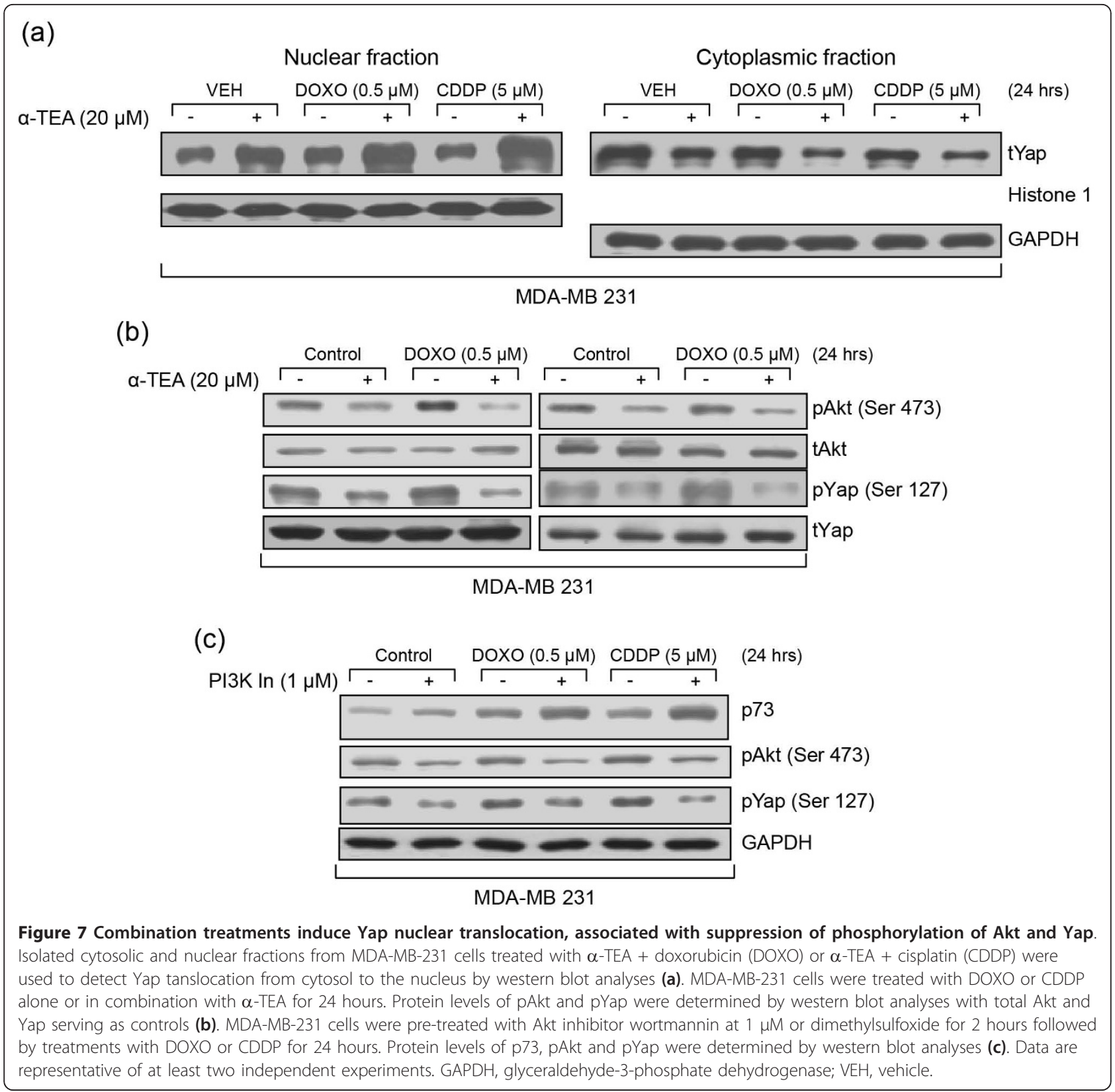

could activate p53 reporter activity, increase expression of p53 target genes such as p21(Waf1), DR5 and TRAIL, and induce apoptosis in p53-deficient colon cancer cells [35]. Some of these compounds activated a p53 response by increasing p73 expression, and knockdown of p73 with siRNA reduced their ability to activate p53 reporter activity while other compounds acted in a p73-independent fashion [35]. In addition, they characterized a derivative of the plant alkaloid ellipticine as an anticancer agent that induces p73 and DR5 protein expression in a p53-deficient human colon carcinoma cell line [43]. Neither of these studies, however, showed direct evidence that p73 was regulating DR5 transcription. To the best of our knowledge, there is no direct evidence showing that p73 regulates DR5 transcription other than the lung cancer studies [42]. In addition, there is no evidence to indicate that p73 transcriptionally regulates $\mathrm{Bcl}-2$. The present study thus demonstrates, for the first time, that both DR5 and Bcl-2 are mediated at the transcriptional level by p73 in p53 mutant, TNBC MDA-MB-231 and BT-20 human breast cancer cells treated with $\alpha$-TEA combined with DOXO or CDDP as determined by siRNA knockdown assays. Our previous data showed that DR5 is involved in $\alpha$-TEA-induced apoptosis since siRNA knockdown of DR5 blocked $\alpha$-TEA-induced apoptosis in MCF-7 and MDA-MB-231 human breast 
cancer cells $[19,20]$. Here, we demonstrated that DR5 is necessary, at least in part, for apoptosis induced by $\alpha$-TEA combination treatments with DOXO or CDDP.

Besides transcriptionally activating p53-mediated apoptotic genes, p73 has been reported to induce ER stress via transactivation of Scotin [44]. Since DR5 and Bcl-2 expression can be regulated by ER stress via CHOP $[45,46]$, and since $\alpha$-TEA has been shown to induce ER stress and CHOP expression [19], we cannot rule out the possibility that $\mathrm{p} 73$ regulates DR5 and Bcl-2 via ER stress in combination treatments. Further studies are needed to address this issue.

p73 is predominantly regulated at the post-translational level in response to DNA-damaging agents. c-Abl and JNK are activated by DNA-damaging agents and both are involved in p73 activation [23,24]. DOXO and CDDP have been shown to regulate $\mathrm{p} 73$ via c-Ab1 $[23,28,29]$. c-Abl regulates p73 via different mechanisms; for example, c-Abl can directly stabilize p 73 via acetylation and phosphorylation of p73 [23,47], and can stabilize p73 and enhance p73 transcriptional activity via phosphorylation of Yap [28]. JNK has been reported to stabilize $\mathrm{p} 73$ via phosphorylation of p73 [24] and via JNK phosphorylation/activation of c-Jun [48]. In addition, JNK also activates p73 via enhancing c-Abl nuclear translocation [49]. In untreated cells, c$\mathrm{Abl}$ is sequestered in the cytosol by 14-3-3 proteins. Upon exposure of cells to DNA damaging agents, JNK is activated and phosphorylates 14-3-3, resulting in the release of c-Abl into the nucleus, an event required for the induction of apoptosis in response to DNA-damaging agents [49]. Published data [50] and the present data show that c-Abl also regulates JNK via phosphorylation, suggesting cross-talk between c-Abl and JNK.

Yap is a transcriptional coactivator, which can interact with the p53 family member p73, resulting in an enhancement of p73's transcriptional activity $[25,26]$ and stability [27]. A potential mechanism of the p73 protein stabilization was recently suggested by Levy and colleagues [27]. Namely, Yap competes with Itch, an E3 ubiquitin ligase involved in degradation of p73, for binding to p73 at the PPXY motif. Furthermore, Yap activity can be regulated by c-Abl via phosphorylation at Tyr-357, leading to a more stable form of Yap that exhibits a higher affinity to p73 [27]. Yap can be negatively regulated by Akt $[30,51]$. Akt induces Yap phosphorylation at Ser-127, resulting in Yap cytosolic localization since phosphorylation of Yap at Ser-127 promotes Yap binding with 14-3-3 [30]. Yap activation can thus be regulated in a positive manner by $\mathrm{c}-\mathrm{Abl}$ and in a negative manner by Akt. DNA damage can activate survival mediator Akt, resulting in reducing the anticancer efficacy of DNA-damaging drugs. DOXO or CDDP induces activation of Akt in some cell lines [52,53]. Likewise, our data show that DOXO and CDDP induce elevated levels of
pAkt not only in MDA-MB-231 cells (Figure 7), but also in MCF-7, MDA-MB-453 and BT-20 cells (data not shown). As expected, Akt inhibitors have been reported to enhance the anticancer effect of DOXO in MDAMB-231 cells [54]. Data reported here show that Akt inhibitor wortmannin enhanced DOXO-mediated and CDDP-mediated increases in 733 protein expression, which is associated with downregulation of pAkt and pYap (Ser-127) in MDA-MB-231 cells. Taken together, these data suggest that Akt activation upon DNA damage may counteract p73 activation induced by JNK and c-Abl via inhibition of Yap nuclear translocation. Our data thus suggest that Yap nuclear translocation plays an important role in p73 activation and that suppression of pAkt and its inhibitory phosphorylation of pYap contributes to enhanced Yap nuclear translocation in combination treatments.

How $\alpha$-TEA induces p73 protein expression is not fully understood. We previously reported that JNK is involved in regulation of p73 in $\alpha$-TEA-induced apoptosis of human breast cancer cells [19]. In the present study, we found that $\alpha$-TEA also induces increased levels of pc-Abl and Yap nuclear translocation, as well as suppresses pAkt and pYap, suggesting that c-Abl and Yap, as well as downregulation of pAkt/pYap, are also involved in $\alpha$-TEA-induced apoptosis. Noxa has been identified as a downstream mediator of p73 in $\alpha$-TEAinduced apoptosis [17]. Whether other p53-mediated genes, such as Fas, DR5, Bax and $\mathrm{Bcl}-2$, are regulated by 73 following $\alpha$-TEA treatment, however, has not been investigated. Since recent data show that ER stressmediated CHOP contributes to $\alpha$-TEA-induced upregulation of DR5 and downregulation of Bcl-2 [19], it will be important for future studies to address whether both CHOP and p73 contribute to DR5 upregulation and $\mathrm{Bcl}-2$ downregulation in $\alpha$-TEA-induced apoptosis.

Mechanisms mediating the combined anticancer effects of $\alpha$-TEA + DOXO or $\alpha-$ TEA + CDDP are diverse and not completely understood. These studies identified p73 as a key player in combination treatment-induced apoptosis. In addition, data show that c-Abl, JNK and Yap play roles in combination treatment-induced activation of p73. It is important to note that although both $\alpha$-TEA and DNA-damaging drugs DOXO or CDDP induce increased levels of pc-Ab1 and pJNK, only $\alpha$-TEA and the combination of $\alpha$-TEA + DOXO or $\alpha$-TEA + CDDP induce Yap nuclear translocation, which is associated with inhibition of pAkt (Ser-473) and Akt-phosphorylated pYap (Ser-127). Furthermore, a phosphoinositide 3kinase/Akt inhibitor was shown to enhance DOXO and CDDP upregulation of p73, which was also associated with downregulation of pAkt and pYap. Taken together, these data suggest that downregulation of pAkt and the pAkt-mediated inactive form of Yap play important roles 
in p73 activation and apoptosis in combination treatments. $\alpha$-TEA thus cooperates with DOXO or CDDP to induce p73 protein expression and apoptosis not only via activation of c-Abl and JNK, but also via activation of Yap, which may be regulated positively by $\mathrm{c}-\mathrm{Abl}$ and negatively by Akt. Based on published reports and the data presented here we proposed signaling events necessary for combination treatment-induced apoptosis in p53 mutant, TNBC cells (Figure 8).

\section{Conclusions}

In summary, the data demonstrate that $\alpha$-TEA, a small bioactive lipid, cooperates with DNA-damaging agents DOXO and CDDP to induce apoptosis in human breast cancer cells via targeting p53-inducible apoptotic-related genes in a p73-dependent manner. These studies highlight the potential for activation of $\mathrm{p} 73$ as a promising target for treatment of p53 mutant, TNBC and identify $\alpha$-TEA as an important candidate agent.

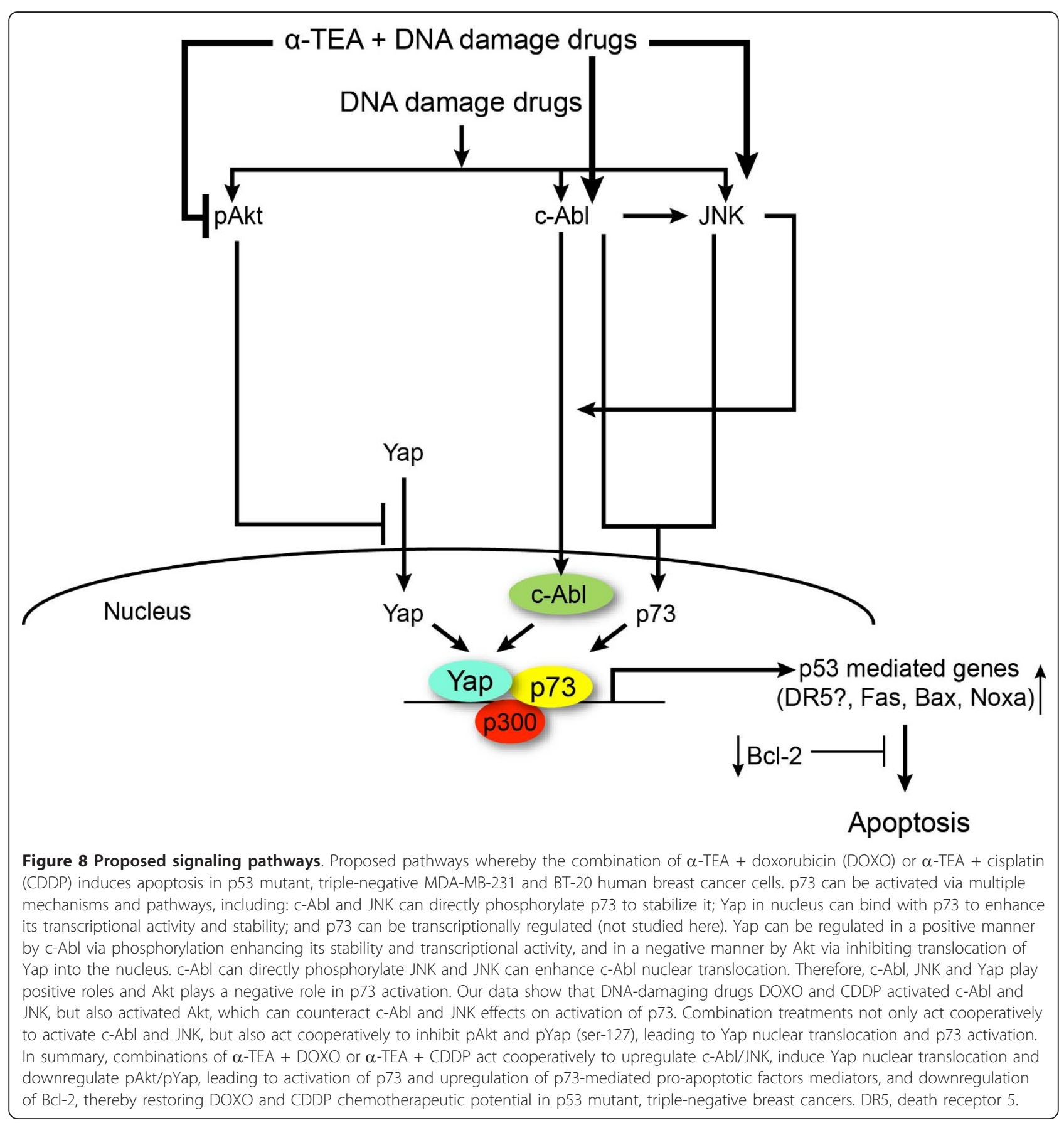




\section{Abbreviations}

a-TEA: RRR-a-tocopherol ether-linked acetic acid analog; CDDP: cisplatin; DOXO: doxorubicin; DR5: death receptor 5; ER: estrogen receptor; FBS: fetal bovine serum; FITC: fluorescein isothiocyanate; JNK: c-Jun N-terminal kinase; MEM: modified Eagle's medium; p-Akt: phospho-Akt; PARP: poly(ADP-ribose) polymerase; PCR: polymerase chain reaction; PI: propidium iodide; pJNK: phospho-c-Jun N-terminal kinase; RT: reverse transcriptase; siRNA: small interfering RNA; TNBC: triple-negative breast cancers; Yap: Yes-associated protein.

\section{Acknowledgements}

The present work was supported by grant to WY from DOD Grant 200802949, grant to BGS and KK from the Clayton Foundation for Research, and a grant to RT from NIEHS/NIH Toxicology Training Grant 5T32ES007247. The funding agencies have no role in study design; in the collection, analysis, and interpretation of data; in the writing of the manuscript; and in the decision to submit the manuscript for publication.

\section{Author details}

${ }^{1}$ School of Biological Sciences/C0900, University of Texas, 1 University Station, Austin, TX 78712, USA. ${ }^{2}$ Department of Nutritional Sciences/A2703, University of Texas, University Station, Austin, TX 78712, USA.

\section{Authors' contributions}

RT, WY, BGS and KK conceived and designed the study, analyzed the data, and drafted the manuscript. WY helped in cell culture study and RT performed all experiments.

\section{Competing interests}

US and international patents on a-TEA are held by the Research Development Foundation. KK, BGS and WY are listed as inventors. No commercial applications or financial gain have been realized.

Received: 16 August 2010 Revised: 16 November 2010

Accepted: 7 January 2011 Published: 7 January 2011

\section{References}

1. Oakman C, Viale G, Di Leo A: Management of triple negative breast cancer. Breast 2010, 19:312-321.

2. Isakoff SJ: Triple-negative breast cancer: role of specific chemotherapy agents. Cancer J 2010, 16:53-61.

3. Yoshida K, Miki Y: The cell death machinery governed by the p53 tumor suppressor in response to DNA damage. Cancer Sci 2010, 101:831-835.

4. Flores E, Tsai K, Crowley D, Sengupta S, Yang A, McKeon F, Jacks T: p63 and $\mathrm{p} 73$ are required for $\mathrm{p} 53$-dependent apoptosis in response to DNA damage. Nature 2002, 416:560-564.

5. Aas T, Børresen AL, Geisler S, Smith-Sørensen B, Johnsen H, Varhaug JE, Akslen LA, Lønning PE: Specific p53 mutations are associated with de novo resistance to doxorubicin in breast cancer patients. Nat Med 1996 2:811-814

6. Branch P, Masson M, Aquilina G, Bignami M, Karran P: Spontaneous development of drug resistance: mismatch repair and p53 defects in resistance to cisplatin in human tumor cells. Oncogene 2000, 19:3138-3145.

7. Jost CA, Marin MC, Kaelin WG Jr: p73 is a simian [correction of human] p53-related protein that can induce apoptosis. Nature 1997, 389:191-194.

8. Hainaut P, Soussi T, Shomer B, Hollstein M, Greenblatt M, Hovig E, Harris CC, Montesano R: Database of p53 gene somatic mutations in human tumors and cell lines: updated compilation and future prospects. Nucleic Acids Res 1997, 25:151-157.

9. Ozaki T, Nakagawara A: p73, a sophisticated p53 family member in the cancer world. Cancer Sci 2005, 96:729-737.

10. Irwin MS, Kondo K, Marin MC, Cheng LS, Hahn WC, Kaelin WG Jr: Chemosensitivity linked to p73 function. Cancer Cell 2003, 3:403-410.

11. Vayssade M, Haddada H, Faridoni-Laurens L, Tourpin S, Valent A, Bénard J, Ahomadegbe JC: p73 functionally replaces p53 in Adriamycin-treated, p53-deficient breast cancer cells. Int J Cancer 2005, 116:860-869.

12. Lawson KA, Anderson K, Snyder RM, Simmons-Menchaca M, Atkinson J, Sun LZ, Bandyopadhyay A, Knight V, Gilbert BE, Sanders BG, Kline K: Novel vitamin $E$ analogue decreases syngeneic mouse mammary tumor burden and reduces lung metastasis. Mol Cancer Ther 2003, 2:437-444.
13. Kline K, Lawson KA, Yu W, Sanders BG: Vitamin E and cancer. Vitam Horm 2007, 76:435-461.

14. Hahn T, Fried K, Hurley LH, Akporiaye ET: Orally active atocopheryloxyacetic acid suppresses tumor growth and multiplicity of spontaneous murine breast cancer. Mol Cancer Ther 2009, 8:1570-1578.

15. Jia $L, Y u$ W, Wang $P$, Sanders BG, Kline $K$ : In vivo and in vitro studies of anticancer actions of $\mathrm{a}-\mathrm{TEA}$ for human prostate cancer cells. Prostate 2008, 68:849-860.

16. Jia L, Yu W, Wang P, Li J, Sanders BG, Kline K: Critical roles for JNK, C-Jun, and Fas/FasL-signaling in vitamin $\mathrm{E}$ analog-induced apoptosis in human prostate cancer cells. Prostate 2008, 68:427-441.

17. Wang P, Yu W, Hu Z, Jia L, lyer VR, Sanders BG, Kline K: Involvement of JNK/p73/NOXA in vitamin E analog-induced apoptosis of human breast cancer cells. Mol Carcinog 2008, 47:436-445.

18. Shun MC, Yu W, Park SK, Sanders BG, Kline K: Downregulation of epidermal growth factor receptor expression contributes to a-TEA's proapoptotic effects in human ovarian cancer cell lines. J Oncol 2010, 2010:824571.

19. Tiwary R, Yu W, Li J, Park SK, Sanders BG, Kline K: Role of endoplasmic reticulum stress in a-TEA mediated TRAIL/DR5 death receptor dependent apoptosis. PLOS ONE 2010, 5:e11865.

20. Yu W, Tiwary R, Li J, Park SK, Jia L, Xiong A, Simmons-Menchaca M, Sanders BG, Kline K: a-TEA induces apoptosis of human breast cancer cells via activation of TRAIL/DR5 death receptor pathway. Mol Carcinog 2010, 49:964-973.

21. Park SK, Sanders BG, Kline K: Tocotrienols induce apoptosis in breast cancer cell lines via an endoplasmic reticulum stress-dependent increase in extrinsic death receptor signaling. Breast Cancer Res Treat 2010, 124:361-375.

22. Yu W, Sanders BG, Kline K: RRR-a-tocopheryl succinate-induced apoptosis of human breast cancer cells involves Bax translocation to mitochondria. Cancer Res 2003, 63:2483-2491.

23. Gong JG, Costanzo A, Yang HQ, Melino G, Kaelin WG Jr, Levrero M, Wang JY: The tyrosine kinase c-Abl regulates p73 in apoptotic response to cisplatin-induced DNA damage. Nature 1999, 399:806-809.

24. Jones EV, Dickman MJ, Whitmarsh AJ: Regulation of p73-mediated apoptosis by c-Jun N-terminal kinase. Biochem J 2007, 405:617-623.

25. Strano S, Munarriz E, Rossi M, Castagnoli L, Shaul Y, Sacchi A, Oren M, Sudol M, Cesareni G, Blandino G: Physical interaction with Yes-associated protein enhances p73 transcriptional activity. J Biol Chem 2001, 276:15164-15173.

26. Strano S, Monti O, Pediconi N, Baccarini A, Fontemaggi G, Lapi E, Mantovani F, Damalas A, Citro G, Sacchi A, Del Sal G, Levrero M, Blandino G: The transcriptional coactivator Yes-associated protein drives p73 gene-target specificity in response to DNA damage. Mol Cell 2005, 18:447-459.

27. Levy D, Adamovich Y, Reuven N, Shaul Y: The Yes-associated protein 1 stabilizes $\mathrm{p} 73$ by preventing Itch-mediated ubiquitination of p73. Cell Death Differ 2007, 14:743-751.

28. Levy D, Adamovich Y, Reuven N, Shaul Y: Yap1 phosphorylation by c-Abl is a critical step in selective activation of proapoptotic genes in response to DNA damage. Mol Cell 2008, 29:350-361.

29. Downward J, Basu S: YAP and p73: a complex affair. Mol Cell 2008, 32:749-750.

30. Basu S, Totty NF, Irwin MS, Sudol M, Downward J: Akt phosphorylates the Yes-associated protein, YAP, to induce interaction with 14-3-3 and attenuation of p73-mediated apoptosis. Mol Cell 2003, 11:11-23.

31. Strano S, Blandino G: p73-mediated chemosensitivity: a preferential target of oncogenic mutant p53. Cell Cycle 2003, 2:348-349.

32. Chung J, Irwin MS: Targeting the p53-family in cancer and chemosensitivity: triple threat. Curr Drug Targets 2010, 11:667-681.

33. Irwin MS: Family feud in chemosensitivity: p73 and mutant p53. Cell Cycle 2004, 3:319-323.

34. Zhu J, Nozell S, Wang J, Jiang J, Zhou W, Chen X: p73 cooperates with DNA damage agents to induce apoptosis in MCF7 cells in a p53dependent manner. Oncogene 2001, 20:4050-4057.

35. Wang W, Kim SH, El-Deiry WS: Small-molecule modulators of p53 family signaling and antitumor effects in p53-deficient human colon tumor xenografts. Proc Natl Acad Sci USA 2006, 103:11003-11008.

36. Haupt S, Berger M, Goldberg Z, Haupt Y: Apoptosis - the p53 network. J Cell Sci 2003, 116:4077-4085. 
37. Bredow $\mathrm{S}$, Juri DE, Cardon $\mathrm{K}$, Tesfaigzi Y: Identification of a novel Bcl-2 promoter region that counteracts in a p53-dependent manner the inhibitory P2 region. Gene 2007, 404:110-116.

38. Moll UM, Slade N: p63 and p73: roles in development and tumor formation. Mol Cancer Res 2004, 2:371-386.

39. Schilling T, Schleithoff ES, Kairat A, Melino G, Stremmel W, Oren M, Krammer PH, Müller M: Active transcription of the human FAS/CD95/ TNFRSF6 gene involves the p53 family. Biochem Biophys Res Commun 2009, 387:399-404.

40. Amin AR, Paul RK, Thakur VS, Agarwal ML: A novel role for $p 73$ in the regulation of Akt-Foxo1a-Bim signaling and apoptosis induced by the plant lectin, Concanavalin A. Cancer Res 2007, 67:5617-5621.

41. Melino G, Bernassola F, Ranalli M, Yee K, Zong WX, Corazzari M, Knight RA, Green DR, Thompson C, Vousden KH: p73 induces apoptosis via PUMA transactivation and Bax mitochondrial translocation. J Biol Chem 2004, 279:8076-8083.

42. Zhu J, Jiang J, Zhou W, Chen X: The potential tumor suppressor p73 differentially regulates cellular p53 target genes. Cancer Res 1998, 58:5061-5065.

43. Lu C, Wang W, El-Deiry WS: Non-genotoxic anti-neoplastic effects of ellipticine derivative NSC176327 in p53-deficient human colon carcinoma cells involve stimulation of p73. Cancer Biol Ther 2008, 7:2039-2046.

44. Terrinoni A, Ranalli M, Cadot B, Leta A, Bagetta G, Vousden KH, Melino G: p73- $a$ is capable of inducing scotin and ER stress. Oncogene 2004, 23:3721-3725.

45. McCullough KD, Martindale JL, Klotz LO, Aw TY, Holbrook NJ: Gadd153 sensitizes cells to endoplasmic reticulum stress by down-regulating $\mathrm{Bcl} 2$ and perturbing the cellular redox state. Mol Cell Biol 2001, 21:1249-1259.

46. Yamaguchi $\mathrm{H}$, Wang HG: CHOP is involved in endoplasmic reticulum stress-induced apoptosis by enhancing DR5 expression in human carcinoma cells. J Biol Chem 2004, 279:45495-45502.

47. Costanzo A, Merlo P, Pediconi N, Fulco M, Sartorelli V, Cole PA, Fontemaggi G, Fanciulli M, Schiltz L, Blandino G, Balsano C, Levrero M: DNA damage-dependent acetylation of p73 dictates the selective activation of apoptotic target genes. Mol Cell 2002, 9:175-186.

48. Toh WH, Siddique MM, Boominathan L, Lin KW, Sabapathy K: c-Jun regulates the stability and activity of the p53 homologue, p73. J Biol Chem 2004, 279:44713-44722

49. Yoshida K, Yamaguchi T, Natsume T, Kufe D, Miki Y: JNK phosphorylation of 14-3-3 proteins regulates nuclear targeting of c-Abl in the apoptotic response to DNA damage. Nat Cell Biol 2005, 7:278-285.

50. Kamath R, Jiang Z, Sun G, Yalowich JC, Baskaran R: C-Abl kinase regulates curcumin-induced cell death through activation of c-Jun N-terminal kinase. Mol Pharmacol 2007, 71:61-72.

51. Lapi E, Di Agostino S, Donzelli S, Gal H, Domany E, Rechavi G, Pandolfi PP, Givol D, Strano S, Lu X, Blandino G: PML, YAP, and p73 are components of a proapoptotic autoregulatory feedback loop. Mol Cell 2008, 32:803-814.

52. Li X, Lu Y, Liang K, Liu B, Fan Z: Differential responses to doxorubicininduced phosphorylation and activation of Akt in human breast cancer cells. Breast Cancer Res 2005, 7:R589-R597.

53. Belyanskaya LL, Hopkins-Donaldson S, Kurtz S, Simões-Wüst AP, Yousefi S, Simon HU, Stahel R, Zangemeister-Wittke U: Cisplatin activates Akt in small cell lung cancer cells and attenuates apoptosis by survivin upregulation. Int J Cancer 2005, 117:755-763.

54. Wang YA, Johnson SK, Brown BL, Dobson PR: Differential enhancement of the anti-cancer effect of doxorubicin by Akt inhibitors on human breast cancer cells with differing genetic backgrounds. Oncol Rep 2009, 21:437-442.

\section{doi:10.1186/bcr2801}

Cite this article as: Tiwary et al: $\alpha$-TEA cooperates with

chemotherapeutic agents to induce apoptosis of p53 mutant,

triple-negative human breast cancer cells via activating p73. Breast

Cancer Research 2011 13:R1.

\section{Submit your next manuscript to BioMed Central and take full advantage of:}

- Convenient online submission

- Thorough peer review

- No space constraints or color figure charges

- Immediate publication on acceptance

- Inclusion in PubMed, CAS, Scopus and Google Scholar

- Research which is freely available for redistribution 